\title{
Clinical aspects of symptomatic hyponatremia
}

\author{
Dirk Weismann', Andreas Schneider ${ }^{1}$ and Charlotte Höybye ${ }^{2,3}$
}

${ }^{1}$ Department of Internal Medicine I, Intensivcare Unit, University Hospital of Würzburg, Würzburg, Germany ${ }^{2}$ Department of Endocrinology, Metabolism and Diabetology, Karolinska University Hospital, Stockholm, Sweden

${ }^{3}$ Department of Molecular Surgery and Medicine, Karolinska Institute, Stockholm, Sweden

\author{
Correspondence \\ should be addressed \\ to D Weismann \\ Email \\ weismann_d@ukw.de
}

\begin{abstract}
Hyponatremia (HN) is a common condition, with a large number of etiologies and a complicated treatment. Although chronic HN has been shown to be a predictor of poor outcome, sodium-increasing treatments in chronic stable and asymptomatic HN have not proven to increase life expectancy. For symptomatic HN, in contrast, the necessity for urgent treatment has broadly been accepted to avoid the development of fatal cerebral edema. On the other hand, a too rapid increase of serum sodium in chronic HN may result in cerebral damage due to osmotic demyelinisation. Recently, administration of hypertonic saline bolus has been recommended as first-line treatment in patients with moderate-to-severe symptomatic HN. This approach is easy to memorize and holds the potential to greatly facilitate the initial treatment of symptomatic HN. First-line treatment of chronic $\mathrm{HN}$ is fluid restriction and if ineffective treatment with tolvaptan or in some patients other agents should be considered. A number of recommendations and guidelines have been published on $\mathrm{HN}$. In the present review, the management of patients with $\mathrm{HN}$ in relation to everyday clinical practice is summarized with focus on the acute management.
\end{abstract}

\author{
Key Words \\ hyponatremia \\ - clinical
}

\section{Introduction}

Hyponatremia $(\mathrm{HN})$ is the most common electrolyte disturbance in hospitalized patients constituting at least about $30 \%$ of patients in medical, surgical and psychiatric wards $(1,2)$. The syndrome of inappropriate antidiuresis (SIAD) accounts for about $50 \%$ of all cases, whereas $\mathrm{HN}$ in cirrhosis and congestive heart failure ranges from $20 \%$ to $25 \%$, each (3). In euvolemic patients, SIAD accounts for about $95 \%$ of cases.

Two major complications are framing the clinical spectrum of hyponatremia (HN) (4): first, cerebral edema due to untreated $\mathrm{HN}$, and second, cerebral damage due to overcorrection of HN. Balancing the risks and benefits of treatment against non-treatment was - and still is - a challenge $(5,6)$. The perception, that acute and chronic HN need different treatment, has greatly improved the care of HN patients since the eighties (7). Today, it is accepted, that chronic $\mathrm{HN}$ is associated with increased morbidity and mortality $(8,9)$, whereas the long-term benefits of increasing serum sodium (sNA) in chronic HN is still unclear (10). In the presence of overt $\mathrm{HN}$-associated symptoms, instead, the need of (urgent) treatment has since long been accepted $(6,11)$. During the years, there has been discussions regarding the maximum rate of correction, which can safely be applied, and a gradual decrease in recommended upper limits over time can be observed $(10,12)$.

$\mathrm{HN}$ is a complicated condition with a large number of etiologies and treatment options. From a practical point of view, the treating physician needs to know, which symptoms qualify for which treatment, and which
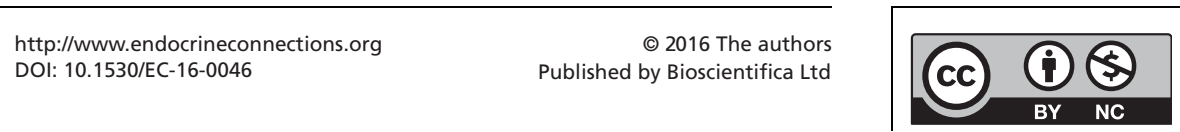

This work is licensed under a Creative Commons Attribution-NonCommercial 4.0 International License. 
measures comply with the steadily decreasing range of accepted maximum increases in sNA. A number of recommendations and guidelines have been published for the guidance on HN. The aim of the present review was to summarize the management of patients with $\mathrm{HN}$ in relation to everyday clinical practice with focus on the acute management.

\section{Pathophysiology}

$\mathrm{HN}$, defined as a sNA $<135 \mathrm{mmol} / \mathrm{L}$, is primarily a disorder of water balance, with a relative excess of body water compared with total body sodium (13). In most cases, an altered vasopressin (ADH) regulation is responsible (14). Vasopressin regulates the reabsorption of water by increasing the permeability of cell membranes via aquaporins in the collecting duct of the kidney (15). The release of vasopressin from the posterior pituitary gland is regulated by the osmolality of the serum (15). In this context, it is important to differentiate between total osmolality and effective osmolality (tonicity). Total osmolality is defined as the concentration of all solutes in a given weight of water $(\mathrm{mOsm} / \mathrm{kg})$, and effective osmolality refers to the number of osmoles that contribute to water movement between the intracellular and extracellular compartment (13). Only effective solutes create osmotic pressure gradients across cell membranes leading to osmotic movement of water between the intracellular and extracellular fluid compartments (13). In the majority of cases, HN reflects low effective osmolality (hypotonicity), which causes cellular edema. HN may also appear as non-hypotonic hyponatremia, and the type of irrigant used, e.g. mannitol, glycine, sorbitol, dextrose, makes a difference in the type of therapy that should be given (13).

The adaptation of the brain to an increase in plasma-osmolality consists of very different and much slower mechanisms compared with the fast adaptations in decreasing osmolality $(16,17)$. Overcorrection in $\mathrm{HN}$ refers to situations in which cerebral adaptations are overstrained, increasing the risk for the osmotic demyelinisation syndrome (18). Based on this knowledge, sNA is recommended not to raise more than $10-12 \mathrm{mmol} / \mathrm{L}$ during the first $24 \mathrm{~h}$, sometimes even a maximum increase of as low as $6-8 \mathrm{mmol} / \mathrm{L}$ is advocated (19). Limiting the increase of sNA to $6 \mathrm{mmol} / \mathrm{L}$ per day is challenging as sNA changes are often unpredictable (20).

\section{Definitions and classification}

To diagnose acute HN, sNA levels must have shown to be normal within the last $48 \mathrm{~h}$ before onset of $\mathrm{HN}$ (21). All cases that do not meet this criterion are defined as chronic. This distinction is important as acute HN can be corrected rapidly, whereas chronic $\mathrm{HN}$ requires a slow, controlled rise in sNA.

The degree of $\mathrm{HN}$ can be defined as mild (135-130 mmol/L), intermediate $(129-125 \mathrm{mmol} / \mathrm{L})$ and profound $(<125 \mathrm{mmol} / \mathrm{L})$. However, the degree of $\mathrm{HN}$ poorly correlates with the level of seriousness in the individual patient $(22,23)$. Instead, the European Practice Guidelines suggest using symptoms as a marker for severity (13). Symptoms range from harmless nausea to lifethreatening coma. According to the practice guidelines, we adopted the terms asymptomatic, moderately symptomatic and severely symptomatic to clinically estimate and characterize the severity of HN (Table 1).

It is common to consider $\mathrm{HN}$ without overt symptoms to be asymptomatic (24), but it has been questioned whether HN can be asymptomatic at all (25). Data suggest improved quality of life after treatment of chronic HN in cancer patients (26). However, assessment of subtle symptoms usually requires additional evaluation and testing in contrast to the more clear diagnosis of severely or moderately symptomatic $\mathrm{HN}$.

According to the practice guidelines, neurologic impairment triggers intervention with hypertonic saline as described in Tables 2 and 3. In asymptomatic patients or those who have subtle signs of $\mathrm{HN}$, a diagnostic work-up should be initiated before treatment is started (see the 'Asymptomatic hyponatremia' section below).

Table 1 Classification of HN according to symptoms (according to Spasovski et al. 2014 (10)).

\begin{tabular}{lll}
\hline $\begin{array}{l}\text { Severity } \\
\text { Asymptomatic or subtle symptoms }\end{array}$ & $\begin{array}{l}\text { Symptoms } \\
\text { after detailed investigation }\end{array}$ & $\begin{array}{l}\text { Concentration and } \\
\text { cognitive deficits } \\
\text { Gait disturbances } \\
\text { Osteoporosis }\end{array}$ \\
& $\begin{array}{l}\text { Headache } \\
\text { Coderate }\end{array}$ & Confusion \\
Severe & Vomiting \\
& Cardiorespiratory distress \\
& Somnolence \\
& Seizures \\
& Coma
\end{tabular}

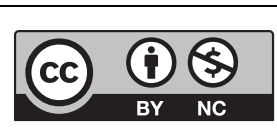

This work is licensed under a Creative Commons Attribution-NonCommercial 4.0 International License. 
Table 2 Treatment of severely symptomatic hyponatremia.

Spasovski et al. 2014 (10)

1. First bolus $(150 \mathrm{~mL} 3 \%$ saline $/ 20 \mathrm{~min})$

2. Check sNa

3. Second bolus

4. Check sNa

5. Repeat step 3, if treatment goals are not achieved

Treatment goals

1. Increase in $\mathrm{sNa}$ by $5 \mathrm{mmol} / \mathrm{L}$ in the first hour

2. Relieve of severe symptoms

Follow-up treatment

- $0.9 \%$ Saline until cause-specific treatment is started

- Check sNA after 6 and $12 \mathrm{~h}$ and daily afterward.

- Limit sNA increase to $10 \mathrm{mmol} / \mathrm{L}$ in the first $24 \mathrm{~h}$ and to $8 \mathrm{mmol} / \mathrm{L}$ thereafter until sNA reaches $130 \mathrm{mmol} / \mathrm{L}$

\section{Diagnostic work-up}

During the initial work-up, the cause of $\mathrm{HN}$ is correctly diagnosed in only about $50 \%$ of cases (27). Although the correct diagnosis greatly facilitates treatment $(28,29)$, physicians should be familiar with the more often and the most importantly occurring clinical situations, such as acute HN, volume depletion, SIAD and adrenal insufficiency. The assessment of volume status is essentially the first step. Overt hypervolemia and hypovolemia can readily be identified, whereas the diagnosis of euvolemia is often challenging. Infusion of isotonic saline and the subsequent changes in sNA can be used to rule out subtle hypovolemia (see the 'Overcorrection and deterioration of hyponatremia' section below). The diagnosis of SIAD is based on the criteria published by Schwartz and Bartter (30) in their initial report on 1957, and, the diagnosis of SIAD is still done based on exclusions. Essential criteria for the diagnosis of SIAD consist of plasma sodium $<135 \mathrm{mmol} / \mathrm{L}$, plasma-osmolality $<275 \mathrm{mOsm} / \mathrm{kg}$, urine osmolality $>100 \mathrm{mOsm} / \mathrm{kg}$, euvolemia, urine sodium $>20 \mathrm{mmol} / \mathrm{L}$ (without diuretics), normal thyroid and adrenal function and no treatment with diuretics. Supplemental criteria include low serum concentrations of uric acid and urea, a fractional urea excretion $>55 \%$, a fractional uric acid

Table 3 Treatment of moderately symptomatic hyponatremia. Spasovski et al. 2014 (10).

1. One bolus of $150 \mathrm{~mL} 3 \%$ hypertonic saline

2. Check sNa at 1, 6 and $12 \mathrm{~h}$ and daily thereafter

3. Aim for at least $5 \mathrm{mmol} / \mathrm{L}$ increase in $\mathrm{sNa}$ in $24 \mathrm{~h}$

4. Limit sNa increase to $10 \mathrm{mmol} / \mathrm{L}$ in the first $24 \mathrm{~h}$ and $8 \mathrm{mmol} / \mathrm{L}$ thereafter until sNa reaches $130 \mathrm{mmol} / \mathrm{L}$

5. Stop offending medications, if possible

6. Initiate prompt diagnostic assessment
Sterns et al. 2009 (18)

Bolus of $100 \mathrm{~mL} 3 \%$ i.v. $/ 10 \mathrm{~min}$

Repeat up to 3 times to control symptoms

Control of symptoms, which should be the case after increase of sNa by $4-6 \mathrm{mmol} / \mathrm{L}$ excretion $>12 \%$, the failure to correct sNA after infusion of isotonic saline and a response to fluid restriction $(31,32)$. Measurement of urine osmolality is important. A high urine osmolality of $>500 \mathrm{mOsm} / \mathrm{kg}$ puts the patient at risk for a further deterioration of $\mathrm{HN}$ after infusion of isotonic saline. Also, fluid restriction is unlikely to be beneficial (see the 'Fluid restriction' section below).

Thus, special attention should be given to identify the SIAD as well, so as to exclude adrenal insufficiency.

One study found that out of 139 patients with intermediate-to-profound $\mathrm{HN}$ consecutively treated in a tertiary endocrine center, 28 patients (mean age 68 years) had hypopituitarism (33). In 25 of the 28 patients, hypopituitarism was not recognized before work-up for HN. Importantly, 75\% had nausea or vomiting and $36 \%$ had impaired consciousness or coma. None of these patients had hyperkalemia, and also patients with primary adrenal insufficiency and $\mathrm{HN}$ normal potassium levels have been found (34). Thus, normokalemia in hyponatremic patients cannot rule out adrenal insufficiency. Cortisol is secreted in a certain diurnal rhythm, and single measurements are difficult to evaluate. A random s-cortisol of $440-450 \mathrm{nmol} / \mathrm{L}$ $(15.9-16.3 \mu \mathrm{g} / \mathrm{dL})$ or higher will often exclude adrenal insufficiency $(33,34)$. To rule out adrenal insufficiency, stimulation tests are needed (35), but in the acute situation, administration of hydrocortisone therapy should be initiated as soon as adrenal insufficiency is suspected. The basic laboratory evaluation is summarized in Table 4.

The more symptomatic a patient with $\mathrm{HN}$ is, the less important is the diagnostic work-up, and prompt treatment should be initiated according to Tables 2 and 3 (see the 'Hypertonic sodium chloride infusion' section below).

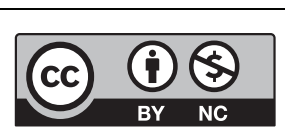

This work is licensed under a Creative Commons Attribution-NonCommercial 4.0 International License. 
Table 4 Basic diagnostic laboratory evaluation.

\begin{tabular}{|c|c|}
\hline Analyte & Comment \\
\hline P-glucose & Pseudohyponatremia \\
\hline S-osmolality & $\begin{array}{l}\text { Confirm hypotonic HN; compare with urine } \\
\text { osmolality }\end{array}$ \\
\hline U-osmolality & $\begin{array}{l}>100 \mathrm{mOsm} / \mathrm{kg} \text { points to SIAD } \\
<200 \mathrm{mOsm} / \mathrm{kg} \text { in primary polydipsia }\end{array}$ \\
\hline $\begin{array}{r}\text { U-Na and U-K } \\
\text { (spot-check) }\end{array}$ & $\begin{array}{l}\text { U-Na }<15 \mathrm{mmol} / \mathrm{L} \text { proves a reduced arterial } \\
\text { blood volume, e.g. in exsiccosis, liver } \\
\text { cirrhosis }\end{array}$ \\
\hline S-Kalium & Hypokalemia is a risk factor for ODS \\
\hline $\begin{array}{l}\text { Liver enzymes, } \\
\text { S-creatinine }\end{array}$ & Liver disease, renal failure \\
\hline $\begin{array}{l}\text { Random cortisol } \\
\text { and ACTH }\end{array}$ & Adrenal insufficiency \\
\hline TSH, fT4, fT3 & Hypothyroidism \\
\hline
\end{tabular}

ODS, osmotic demyelination syndrome; SIAD, syndrome of inappropriate antidiuresis.

\section{Advanced diagnostic approach}

It may be difficult to differentiate primary polydipsia from SIAD in euvolemic patients with a urine osmolality of $>100 \mathrm{mOsm} / \mathrm{kg}$. Here, the combined evaluation of urine osmolality and serum copeptin may be a reliable marker with a sensitivity and specificity of $100 \%$. Copeptin is derived from a pre-pro-hormone, consisting of vasopressin, neurophysin II and copeptin. Thresholds to diagnose primary polydipsia are diluted urine of less than $200 \mathrm{mOsm} / \mathrm{kg}$ and a suppressed copeptin of less than $3 \mathrm{pmol} / \mathrm{L}$ (36). The SIAD, in turn, can accurately be diagnosed using the fractional urea excretion (37).

\section{Treatment of symptomatic hyponatremia}

\section{Treatment goals in symptomatic hyponatremia}

Severely symptomatic $\mathrm{HN}$ as defined in Table 1 is a medical emergency and physicians must make themselves familiar with the treatment. In the two Tables 2 and 3, two recently published recommendations are summarized. Usually an increase of sNA by $5 \mathrm{mmol} / \mathrm{L}$ is sufficient to improve symptoms even in severely symptomatic patients (38). Therefore, the first-hour goal in severely symptomatic $\mathrm{HN}$ is to achieve an increase of sNA by $5 \mathrm{mmol} / \mathrm{L}$ together with a significant clinical improvement in symptoms. In all other cases, the increase should be limited to $10-12 \mathrm{mmol} / \mathrm{L}$ in the first $24 \mathrm{~h}$ and to $8 \mathrm{mmol} / \mathrm{L} /$ day in the following days until a sNA of $130 \mathrm{mmol} / \mathrm{L}$ is obtained. Limiting the increase of sNA is difficult, but is greatly facilitated by the introduction of desmopressin (see the
'Desmopressin' section below) and infusion of glucose 5\% ('free water') in the treatment of hyponatremia.

\section{Overcorrection and deterioration of hyponatremia}

The risk of overcorrection is especially high in patients with volume and sodium depletion e.g. due to vomiting and diarrhea. Volume resuscitation with isotonic saline in $\mathrm{HN}$ may result in an overshooting increase of sNA, because volume resuscitation quickly suppresses $\mathrm{ADH}$ secretion (38). In turn, urine volume increases, whereas sodium reabsorption is still at maximum (38). Plasma sodium rises quickly and, therefore, careful monitoring of hypovolemic patients with hyponatremia who receive isotonic saline is mandatory.

The highest risk for an osmotic demyelinisation syndrome is found in patients with malnutrition, alcoholism, concomitant hypokalemia, advanced liver disease or very pronounced HN (<106 mmol/L) (19). In these patients, more stringent treatment targets are recommended. In the first $24 \mathrm{~h}$, a maximum increase of $8 \mathrm{mmol} / \mathrm{L}$ is reasonable with $6 \mathrm{mmol} / \mathrm{L} /$ day increase in the following days.

In contrast, uncontrolled deterioration with a further decrease in serum sodium may occur after $0.9 \%$ sodium chloride infusion in patients with severe SIAD. Patients with a urine osmolality higher than $500 \mathrm{mOsmol} / \mathrm{mL}$ in the presence of $\mathrm{HN}$ are prone to a further drop in serum sodium.

\section{Desmopressin}

Desmopressin administration to limit $\mathrm{sNa}$ increase has been recommended for a long time (21). A very recent review on the use of desmopressin in HN identified three treatment strategies (19): proactive, reactive and rescue. Proactive was defined as early administration, reactive as administration as soon as a change in sNA or urine output was documented and rescue was defined as administration after treatment targets are exceeded. According to the authors, the overall quality of the reviewed studies was poor, and the proactive approach was based only on one study from a specialized center (39). However, in the proactive group, only $27.6 \%$ exceeded the upper limit of sNA correction of $8 \mathrm{mmol} /$ day in the high-risk population compared with $87.9 \%$ in the reactive group. The proactive approach was combined with the infusion of $3 \%$ hypertonic saline, occasionally with initial bolus infusion. Most patients received desmopressin $2 \mu \mathrm{g}$ every 
$8 \mathrm{~h}$ either intravenously or subcutaneously. Hypertonic saline (3\%) was titrated and stopped whenever a $6 \mathrm{mmol} / \mathrm{L}$ increase was achieved (39).

An observational study on 20 patients treated for severely symptomatic $H N$ in an ICU described the reactive and rescue approach to limit sNA increase (40). Desmopressin doses ranged between $2-4 \mu$ g, repeated dosing was necessary in 12 of 20 patients. The median dosing interval was $25 \mathrm{~h}$. In 11 patients, sNA was re-lowered because the 24-hour limit was exceeded.

Overall, the combined administration of hypertonic saline and desmopressin seemed to facilitate the correction of hyponatremia, and especially, the proactive strategy is a promising approach to prevent overcorrections.

\section{Hypertonic sodium chloride infusion}

The use of 3 and 5\% saline was reported as early as during the initial characterization of SIAD by Schwartz and Bartter (41). Since then, the use of 3\% hypertonic saline has been widely recommend for the correction of profound HN (21). Saline concentration higher than $5 \%$ was used in other conditions, but is not evaluated for the treatment of HN. For example, small volumes (i.e. $250 \mathrm{~mL}$ ) of a $7.5 \%$ saline have been tested during trauma and shock (42). Infusion of $23.4 \%$ and even $30 \%$ saline has been reported for the treatment of refractory intracerebral hypertension $(43,44)$. However, changes in sNA are inconsistently reported in these studies. In one study, the use of $7.2 \%$ saline hydroxyethyl starch (200/0.5) with a rate of $1.4 \mathrm{~mL} / \mathrm{kg}$ and a mean infused volume of $100 \mathrm{~mL}$ resulted in a maximum increase in serum sodium from $143(136-148) \mathrm{mmol} / \mathrm{L}$ to 148 (144-153) mmol/L (45).

The concept of bolus administration was first introduced for treatment of HN after endurance exercise (46) and has later been advocated by Sterns and coworkers (18). In the European Guidelines, a bolus infusion is defined as $150 \mathrm{~mL}$ of $3 \%$ hypertonic saline (13). Although these recommendations are not based on robust clinical data, clinicians may favor this approach due to its simplicity in daily practice.

A recent study (47) investigated the infusion of $500 \mathrm{~mL} 3 \%$ saline over $6 \mathrm{~h}$ in patients with a sNA $<130 \mathrm{mmol} / \mathrm{L}$ and signs of hyponatremic encephalopathy consistent with moderate or severe symptoms. They documented a controlled increase from $114 \pm 0.8 \mathrm{mmol} / \mathrm{L}$ to $123.9 \pm 1 \mathrm{mmol} / \mathrm{L}$ at $24 \mathrm{~h}$ and $128.3 \pm 0.8 \mathrm{mmol} / \mathrm{L}$ at $48 \mathrm{~h}$. In these 64 patients, neurologic symptoms improved within hours, and no osmotic demyelinisation was
() 2016 The authors Published by Bioscientifica Ltd observed. Five patients had significant overcorrection with an increase of sNA $\geq 25 \mathrm{mmol} / \mathrm{L}$ in $48 \mathrm{~h}$. Desmopressin was not used in this study (47).

\section{Acute hyponatremia}

Resorbing irrigate fluids in e.g. transurethral prostate surgery (48), hysteroscopic surgery (49) or during preparation for colonoscopy (50) can cause acute HN. Usually, a normal sNA level from the same day or the day before will document the acute fall in sNA. In one patient, even correction of sNA from $74 \mathrm{mmol} / \mathrm{L}$ to $130 \mathrm{mmol} / \mathrm{L}$ within $7 \mathrm{~h}$ was reported without the occurrence of neurologic deficits (49). In this case, pulmonary edema developed during hysteroscopic surgery together with an acute drop in sNA. Correction was achieved by the administration of furosemide $40 \mathrm{mg}$ together with the infusion of $500 \mathrm{~mL}$ of $3 \%$ hypertonic saline for $1 \mathrm{~h}$ (sNA was $103 \mathrm{mmol} / \mathrm{L}$ thereafter) followed by the infusion of $3 \%$ hypertonic saline for additional $6 \mathrm{~h}(50 \mathrm{~mL} / \mathrm{h})$. Hepp and coworkers also reported 8 additional cases from the literature of which 4 were treated with 3\% saline (49). The other 4 patients were treated with $7 \%, 2 \%$, isotonic saline or furosemide, respectively. Thus, existing but limited data indicate that the rapid correction of sNA into the normal range is advisable in acute $\mathrm{HN}$.

\section{Isotonic saline}

The osmolality of normal saline $(0.9 \%)$ is physiological (308mosmol/L), whereas the concentration of sodium and chloride $(154 \mathrm{mmol} / \mathrm{L}$ each) is increased. Even though sodium concentration is slightly increased, rehydration without altering electrolytes is a major task of administration of normal saline. Thus, a volume effect has to be taken in to account, when normal saline is used to treat hyponatremia. Physiologically, volume resuscitation decreases $\mathrm{ADH}$, which in turn increases diuresis, whereas renal sodium uptake may still be at maximum (38). As a result, a rapid and unpredictable increase of sNA may be observed, especially, in clinically volume-depleted patients with HN. In SIAD, in contrast, the water of normal saline promotes a further volume expansion, whereas the sodium will be excreted in a highly concentrated urine. The net effect will be a further drop in sNA.

In clinically euvolemic patients, two liters of isotonic saline infused over $24 \mathrm{~h}$ can be used to unmask hidden hypovolemia (51). sNA should be monitored every 4-6h during the infusion. An increase in sNA $(>5 \mathrm{mmol} / \mathrm{L})$ points to sodium depletion and discloses SIAD. http://www.endocrineconnections.org DOI: 10.1530/EC-16-0046 
Table 5 Offending medications in hyponatremia.

\begin{tabular}{|c|c|}
\hline Anticancer agents & $\begin{array}{l}\text { Vinca alkaloids; platinum } \\
\text { compounds; alkylating agents }\end{array}$ \\
\hline Antidepressants & Tricyclic AD; SSRI; MAO \\
\hline Anti-epileptic drugs & $\begin{array}{l}\text { Carbamazepine; Valproate; } \\
\text { Oxcarbazepine }\end{array}$ \\
\hline Antihypertensive agents & ACEl; Amlodipine \\
\hline Antipsychotic drugs & Phenothiazines; Butyrophenones \\
\hline Diuretics & $\begin{array}{l}\text { Thiazides; Indapamide; Amiloride; } \\
\text { Loop diuretics }\end{array}$ \\
\hline Proton pump inhibitors & Omeprazol \\
\hline
\end{tabular}

\section{Fluid restriction}

Fluid restriction (FR) is a first-line therapy for euvolemic HN patients with SIAD. According to the hyponatremia registry (3), however, FR was the most widely used but the least effective measure to treat $\mathrm{HN}$. Importantly, FR is ineffective if urine osmolality is high (e.g. $>500 \mathrm{mOsmol} / \mathrm{kg}$ ). To decide about FR, it is important to know the ratio of urine to plasma electrolyte concentration, but according to the registry, these parameters were rarely evaluated. Grant and coworkers proposed the use of the Furst formula (urine $\mathrm{Na}+\mathrm{K} / \mathrm{sNa}$ ) (52) before commencing FR and to choose between FR of $1 \mathrm{~L}$ or $0.5 \mathrm{~L}$ (53). In case of a ratio of $>1$, FR is not recommended at all and a specialist in $\mathrm{HN}$ should be consulted. FR should not be initiated in patients with symptomatic HN, as this is associated with an increase in morbidity and mortality (4). Alternative therapy should be considered if sNA increases $<2 \mathrm{mmol} / \mathrm{L}$ in the first $24-48 \mathrm{~h}$.

\section{Tolvaptans and other treatments}

Tolvaptan is a V2-receptor antagonist approved by the EMA for the treatment of $\mathrm{HN}$ in patients with SIAD (54). The FDA approved Tolvaptan on May 2009 for the treatment of hypervolemic and euvolemic HN (sNA $>125 \mathrm{mmol} / \mathrm{L}$ or less marked symptomatic hyponatremia) including in patients with heart failure and SIAD. Liver enzymes should be monitored and tolvaptan should not be used in patients with liver cirrhosis.

For a detailed presentation of benefits and limitations, we refer the reader to a very recent review by Tomas Berl (55).

In brief, tolvaptan is the only approved specific treatment for SIAD. It has in randomized placebocontrolled trials been shown to effectively increase sNA and to be safe. Treatment with tolvaptan should be initiated in hospital, and sNA should be monitored to avoid rapid overcorrection. Currently, tolvaptan is not recommended in patients with severely symptomatic HN. Treatment with tolvaptan might be indicated for longterm treatment depending on the underlying course of SIAD. Improved survival after correction of asymptomatic HN has not yet been shown and need to be addressed in future studies. Treatment with tolvaptan in SIAD is recommended in all guidelines except the European Society of Endocrinology's guideline.

Other non-specific available treatments are urea, demeclocycline and lithium. Demeclocycline is licensed for treatment of chronic SIAD in France and UK, whereas urea and lithium are not licensed in any country. Previous reports have suggested that urea can also be used to treat hyponatremia $(56,57)$. Moreover, Kengne and coworkers recently showed that rapid correction of severe hyponatremia with urea in rats might carry a lower risk of the osmotic demyelinisation syndrome (ODS) than hypertonic saline or vaptanes, despite similar increase in serum sodium obtained by the three drugs (58). To date, the underlying mechanism for the decreased risk of brain complications is not well understood and further investigations are needed. Treatment with urea for SIAD is recommended in the European Society of Endocrinology's guideline. However, the evidence for treatment with urea a well as with demeclocycline and lithium for $\mathrm{HN}$ is limited, and the support for a generalized use of these drugs is weak.

Table 6 Examples for causal therapy in hyponatremia.

\begin{tabular}{|c|c|c|c|}
\hline Cause & Treatment & Volume status & Comment \\
\hline $\begin{array}{l}\text { Hypertonic dehydration (e.g. vomiting, } \\
\text { diarrhea) }\end{array}$ & Volume resuscitation $0.9 \% \mathrm{NaCl}$ & Hypovolemic & Overcorrection likely! \\
\hline SIAD & FR (?) Vaptanes & Euvolemic & $\begin{array}{l}\text { Deterioration with } \mathrm{NaCl} \\
0.9 \% \text { possible }\end{array}$ \\
\hline Adrenal insufficiency & Glucocorticoid substitution & Euvolemic & Overcorrection likely! \\
\hline Congestive heart failure & Loop diuretics FR & Hypervolemic & \\
\hline Offending medications & Change drug & Euvolemic & \\
\hline Primary polydipsia & FR & Hypervolemic/euvolemic & \\
\hline
\end{tabular}

$F R$, fluid restriction. 


\section{Asymptomatic hyponatremia}

A cause-specific treatment is recommended in asymptomatic $\mathrm{HN}$. Because the etiology of $\mathrm{HN}$ includes a multitude of conditions and therapies $(13,59)$, a diagnostic work-up is essential. Offending medications should be discontinued, if possible (Table 5). The clinical practice guidelines recommend against treatments with the sole aim of increasing $\mathrm{sNa}$ (13). The UK panel of experts does not explicitly comment on this constellation because their algorithm is not symptom based (53). However, the proposed algorithm can be used to identify the underlying diagnosis (see also Table 6). Fluid restriction is recommended in case of euvolemia, and the UK expert panel algorithm guides in the appropriate degree of fluid restriction according to the electrolyte-free water clearance (52).

\section{Conclusion}

$\mathrm{HN}$ has received an increased attention during the last few years, and the literature has increased correspondingly. Therapies for acute and chronic HN differ considerably, and the risk for overcorrecting chronic HN requires a thorough evaluation of the individual patient. HN can be caused by a large number of underlying diseases and an individualized treatment is necessary, which is a challenge in a stressful acute situation. In such situations, identification of patients with symptomatic $\mathrm{HN}$ is useful and administration of hypertonic saline bolus may greatly facilitate the initial treatment. An increase in sNA is recommended to be limited to $10-12 \mathrm{mmol} / \mathrm{L}$ during the first $24 \mathrm{~h}$ and to $8 \mathrm{mmol} / \mathrm{L} /$ day during the following days until a sNA of $130 \mathrm{mmol} / \mathrm{L}$ is obtained. In case of overcorrection and thereby an increased risk of osmotic demyelinisation, desmopressin and infusion of glucose 5\% can be used. First-line treatment of subtle symptomatic chronic $\mathrm{HN}$ is fluid restriction and in case of refractory $\mathrm{HN}$, treatment with vaptans should be considered. The care for patients with $\mathrm{HN}$ is complicated, and a careful individual evaluation is required for obtaining the right management.

\section{Declaration of interest}

Charlotte Höybye has received lecture fees from Otsuka Pharma Scandinavia. The authors declare that there is no conflict of interest that could be perceived as prejudicing the impartiality of this review.

\section{Funding}

This work did not receive any specific grant from any funding agency in the public, commercial, or not-for-profit sector.

\section{References}

1 Hawkins RC. Age and gender as risk factors for hyponatremia and hypernatremia. Clinica Chimica Acta 2003337 169-172. (doi:10.1016/j.cccn.2003.08.001)

2 Upadhyay A, Jaber BL \& Madias NE. Incidence and prevalence of hyponatremia. American Journal of Medicine 2006119 S30-S35. (doi:10.1016/j.amjmed.2006.05.005)

3 Greenberg A, Verbalis JG, Amin AN, Burst VR, Chiodo JA 3rd, Chiong JR, Dasta JF, Friend KE, Hauptman PJ, Peri A, et al. Current treatment practice and outcomes. Report of the hyponatremia registry. Kidney International 201588 167-177. (doi:10.1038/ ki.2015.4)

4 Ayus JC \& Arieff AI. Chronic hyponatremic encephalopathy in postmenopausal women: association of therapies with morbidity and mortality. JAMA 1999281 2299-304. (doi:10.1001/jama.281.24.2299)

5 Berl T. Treating hyponatremia: damned if we do and damned if we don't. Kidney International 199037 1006-1018. (doi:10.1038/ ki.1990.78)

6 Narins RG. Therapy of hyponatremia: does haste make waste? New England Journal of Medicine 1986314 1573-1575. (doi:10.1056/ NEJM198606123142409)

7 Norenberg MD \& Papendick RE. Chronicity of hyponatremia as a factor in experimental myelinolysis. Annals of Neurology $1984 \mathbf{1 5}$ 544-547. (doi:10.1002/ana.410150606)

8 Mohan S, Gu S, Parikh A \& Radhakrishnan J. Prevalence of hyponatremia and association with mortality: results from NHANES American Journal of Medicine 2013126 1127-1137 e1. (doi:10.1016/j. amjmed.2013.07.021)

9 Bavishi C, Ather S, Bambhroliya A, Jneid H, Virani SS, Bozkurt B \& Deswal A. Prognostic significance of hyponatremia among ambulatory patients with heart failure and preserved and reduced ejection fractions. American Journal of Cardiology 2014113 1834-1838. (doi:10.1016/j.amjcard.2014.03.017)

10 Spasovski G, Vanholder R, Allolio B, Annane D, Ball S, Bichet D, Decaux G, Fenske W, Hoorn EJ, Ichai C, et al. Clinical practice guideline on diagnosis and treatment of hyponatraemia. European Journal of Endocrinology 2014170 G1-G47. (doi:10.1530/EJE-13-1020)

11 Ellis SJ. Severe hyponatraemia: complications and treatment. QJM 199588 905-909.

12 Verbalis JG. How does the brain sense osmolality? Journal of the American Society of Nephrology 200718 3056-3059. (doi:10.1681/ ASN.2007070825)

13 Spasovski G, Vanholder R, Allolio B, Annane D, Ball S, Bichet D, Decaux G, Fenske W, Hoorn EJ, Ichai C, et al. Clinical practice guideline on diagnosis and treatment of hyponatraemia. Nephrology Dialysis Transplantation 201429 (Supplement 2) i1-i39. (doi:10.1093/ndt/gfu040)

14 Sherlock M \& Thompson CJ. The syndrome of inappropriate antidiuretic hormone: current and future management options. European Journal of Endocrinology 2010162 (Supplement 1) S13-S18. (doi:10.1530/EJE-09-1057)

15 Park EJ \& Kwon TH. A minireview on vasopressin-regulated aquaporin-2 in kidney collecting duct cells. Electrolyte Blood Press 2015 13 1-6. (doi:10.5049/EBP.2015.13.1.1)

16 Strange K. Regulation of solute and water balance and cell volume in the central nervous system. Journal of the American Society of the Nephrology 19923 12-27.

http://www.endocrineconnections.org
$\begin{array}{lr}\text { DOI: } 10.1530 / E C-16-0046 & 2016 \text { The authors } \\ \end{array}$

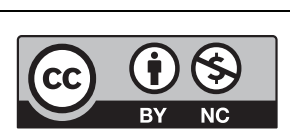

This work is licensed under a Creative Commons Attribution-NonCommercial 4.0 International License. 
17 Pasantes-Morales H \& Cruz-Rangel S. Brain volume regulation: osmolytes and aquaporin perspectives. Neuroscience 2010168 871-884. (doi:10.1016/j.neuroscience.2009.11.074)

18 Sterns RH, Nigwekar SU \& Hix JK. The treatment of hyponatremia. Seminars in Nephrology 200929 282-299. (doi:10.1016/j. semnephrol.2009.03.002)

19 MacMillan TE, Tang T \& Cavalcanti RB. Desmopressin to prevent rapid sodium correction in severe hyponatremia: a systematic review. American Journal of Medicine 2015128 1362.e15-e24. (doi:10.1016/j. amjmed.2015.04.040)

20 Adrogue HJ \& Madias NE. Hypernatremia. New England Journal of Medicine 2000342 1493-1499. (doi:10.1056/NEJM200005183422006)

21 Soupart A \& Decaux G. Therapeutic recommendations for management of severe hyponatremia: current concepts on pathogenesis and prevention of neurologic complications. Clinical Nephrology 199646 149-169.

22 Adrogue HJ \& Madias NE. Diagnosis and treatment of hyponatremia. American Journal of Kidney Diseases 201464 681-684. (doi:10.1053/j. ajkd.2014.06.001)

23 Miller M. Hyponatremia and arginine vasopressin dysregulation: mechanisms, clinical consequences, and management. Journal of the American Geriatrics Society 200654 345-353. (doi:10.1111/j.15325415.2005.00609.x)

24 Nigro N, Winzeler B, Suter-Widmer I, Schuetz P, Arici B, Bally M, Blum C, Bingisser R, Bock A, Huber A, et al. Symptoms and characteristics of individuals with profound hyponatremia: a prospective multicenter observational study. Journal of the American Geriatrics Society 201563 470-475. (doi:10.1111/jgs.13325)

25 Schrier RW. Aldosterone 'escape' vs 'breakthrough'. Nature Reviews Nephrology 20106 61. (doi:10.1038/nrneph.2009.228)

26 Petereit C, Zaba O, Teber I, Lüders H \& Grohé C. A rapid and efficient way to manage hyponatremia in patients with SIADH and small cell lung cancer: treatment with tolvaptan. BMC Pulmonary Medicine 2013 13 55. (doi:10.1186/1471-2466-13-55)

27 Fenske W, Maier SK, Blechschmidt A, Allolio B \& Störk S. Utility and limitations of the traditional diagnostic approach to hyponatremia: a diagnostic study. American Journal of Medicine 2010123 652-657. (doi:10.1016/j.amjmed.2010.01.013)

28 Ayus JC, Krothapalli RK \& Arieff AI. Changing concepts in treatment of severe symptomatic hyponatremia. Rapid correction and possible relation to central pontine myelinolysis. American Journal of Medicine 198578 897-902. (doi:10.1016/0002-9343(85)90209-8)

29 Norenberg MD, Leslie KO \& Robertson AS. Association between rise in serum sodium and central pontine myelinolysis. Annals of Neurology 198211 128-135. (doi:10.1002/ana.410110204)

30 Schwartz WB, Bennett W, Curelop S \& Bartter FC. A syndrome of renal sodium loss and hyponatremia probably resulting from inappropriate secretion of antidiuretic hormone. American Journal of Medicine 195723 529-542. (doi:10.1016/0002-9343(57)90224-3)

31 Verbalis JG. Managing hyponatremia in patients with syndrome of inappropriate antidiuretic hormone secretion. Endocrinologia y Nutricion 201057 (Supplement 2) 30-40. (doi:10.1016/S1575-0922(10)70020-6)

32 Janicic N \& Verbalis JG. Evaluation and management of hypoosmolality in hospitalized patients. Endocrinology and Metabolism Clinics of North America 200332 459-481, vii. (doi:10.1016/S08898529(03)00004-5)

33 Diederich S, Franzen NF, Bähr V \& Oelkers W. Severe hyponatremia due to hypopituitarism with adrenal insufficiency: report on 28 cases. European Journal of Endocrinology 2003148 609-617. (doi:10.1530/ eje.0.1480609)

34 Tzoulis P \& Bouloux PM. Inpatient hyponatraemia: adequacy of investigation and prevalence of endocrine causes. Clinical Medicine 201515 20-24. (doi:10.7861/clinmedicine.15-1-20)

35 de Miguel Novoa P, Vela ET, García NP, Rodríguez MM, Guerras IS, Martínez de Salinas Santamaría Mde L, Masó AA; Área de Conocimiento del Grupo de Neuroendocrino de la SEEN (Grupo
Insuficiencia Adrenal). Guidelines for the diagnosis and treatment of adrenal insufficiency in the adult. Endocrinología y Nutrición 201461 (Supplement 1) 1-35. (doi:10.1016/S1575-0922(14)73526-0)

36 Fenske W, Störk S, Blechschmidt A, Maier SG, Morgenthaler NG \& Allolio B. Copeptin in the differential diagnosis of hyponatremia. Journal of Clinical Endocrinology and Metabolism 200994 123-129. (doi:10.1210/jc.2008-1426)

37 Fenske W, Störk S, Koschker AC, Blechschmidt A, Lorenz D, Wortmann $S$ \& Allolio B. Value of fractional uric acid excretion in differential diagnosis of hyponatremic patients on diuretics. Journal of Clinical Endocrinology and Metabolism 200893 2991-2997. (doi:10.1210/jc.2008-0330)

38 Henry DA. In the clinic: hyponatremia. Annals of Internal Medicine 2015163 ITC1-ITC19. (doi:10.7326/AITC201508040)

39 Sood L, Sterns RH, Hix JK, Silver SM \& Chen L. Hypertonic saline and desmopressin: a simple strategy for safe correction of severe hyponatremia. American Journal of Kidney Diseases 201361 571-578. (doi:10.1053/j.ajkd.2012.11.032)

40 Rafat C, Schortgen F, Gaudry S, Bertrand F, Miguel-Montanes R, Labbé V, Ricard JD, Hajage D \& Dreyfuss D. Use of desmopressin acetate in severe hyponatremia in the intensive care unit. Clinical Journal of the American Society of Nephrology 20149 229-237. (doi:10.2215/CJN.00950113)

41 Bartter FC \& Schwartz WB. The syndrome of inappropriate secretion of antidiuretic hormone. American Journal of Medicine 196742 790-806. (doi:10.1016/0002-9343(67)90096-4)

42 Wade C, Grady J \& Kramer G. Efficacy of hypertonic saline dextran (HSD) in patients with traumatic hypotension: meta-analysis of individual patient data. Acta Anaesthesiologica Scandinavica. Supplementum 1997110 77-79. (doi:10.1111/j.1399-6576.1997. tb05509.x)

43 Suarez JI, Qureshi AI, Bhardwaj A, Williams MA, Schnitzer MS Mirski M, Hanley DF \&, Ulatowski JA. Treatment of refractory intracranial hypertension with $23.4 \%$ saline. Critical Care Medicine 199826 1118-1122. (doi:10.1097/00003246-199806000-00038)

44 Major EH, O'Connor P \& Mullan B. Single bolus 30\% hypertonic saline for refractory intracranial hypertension. Irish Journal of Medical Science 2015184 159-165. (doi:10.1007/s11845-014-1080-9)

45 Harutjunyan L, Holz C, Rieger A, Menzel M, Grond S \& Soukup J. Efficiency of $7.2 \%$ hypertonic saline hydroxyethyl starch $200 / 0.5$ versus mannitol $15 \%$ in the treatment of increased intracranial pressure in neurosurgical patients - a randomized clinical trial [ISRCTN62699180]. Critical Care 20059 R530-R540. (doi:10.1186/cc3767)

46 Noakes T. Fluid replacement during marathon running. Clinical Journal of Sport Medicine 200313 309-318. (doi:10.1097/00042752200309000-00007)

47 Ayus JC, Caputo D, Bazerque F, Heguilen R, Gonzalez CD \& Moritz ML. Treatment of hyponatremic encephalopathy with a 3\% sodium chloride protocol: a case series. American Journal of Kidney Diseases 201565 435-442. (doi:10.1053/j.ajkd.2014.09.021)

48 Demirel I, Ozer AB, Bayar MK \& Erhan OL. TURP syndrome and severe hyponatremia under general anaesthesia. BMJ Case Reports 20122012 bcr-2012-006899. (doi:10.1136/bcr-2012-006899)

49 Hepp P, Jüttner T, Beyer I, Fehm T, Janni W \& Monaca E. Rapid correction of severe hyponatremia after hysteroscopic surgery - a case report. BMC Anesthesiology 201515 85. (doi:10.1186/s12871-0150070-4)

50 Cho YS, Nam KM, Park JH, Byun SH, Ryu JS \& Kim HJ. Acute hyponatremia with seizure and mental change after oral sodium picosulfate/magnesium citrate bowel preparation. Annals of Coloproctology 201430 290-293. (doi:10.3393/ac.2014.30.6.290)

51 Fenske WK, Christ-Crain M, Hörning A, Simet J, Szinnai G, Fassnacht M, Rutishauser J, Bichet DG, Störk S \& Allolio B. A copeptin-based classification of the osmoregulatory defects in the syndrome of inappropriate antidiuresis. Journal of the American Society of Nephrology 201425 2376-2383. (doi:10.1681/ASN.2013080895) 
52 Furst H, Hallows KR, Post J, Chen S, Kotzker W, Goldfarb S, Ziyadeh FN \& Neilson EG. The urine/plasma electrolyte ratio: a predictive guide to water restriction. American Journal of Medical Sciences 2000319 240-244. (doi:10.1016/S0002-9629(15)40736-0)

53 Grant P, Ayuk J, Bouloux PM, Cohen M, Cranston I, Murray RD, Rees A, Thatcher N \& Grossman A. The diagnosis and management of inpatient hyponatraemia and SIADH. European Journal of Clinical Investigation 201545 888-894. (doi:10.1111/eci.12465)

54 Berl T, Quittnat-Pelletier F, Verbalis JG, Schrier RW, Bichet DG, Ouyang J, Czerwiec FS; SALTWATER Investigators. Oral tolvaptan is safe and effective in chronic hyponatremia. Journal of the American Society of Nephrology 201021 705-712. (doi:10.1681/ASN.2009080857)

55 Berl T. Vasopressin antagonists. New England Journal of Medicine 2015 372 2207-2216. (doi:10.1056/NEJMra1403672)

56 Soupart A, Coffernils M, Couturier B, Gankam-Kengne F \& Decaux G. Efficacy and tolerance of urea compared with vaptans for long-term treatment of patients with SIADH. Clinical Journal of the American Society of Nephrology 20127 742-747. (doi:10.2215/CJN.06990711)

57 Decaux G, Unger J, Brimioulle S \& Mockel J. Hyponatremia in the syndrome of inappropriate secretion of antidiuretic hormone. Rapid correction with urea, sodium chloride, and water restriction therapy. JAMA 1982247 471-474. (doi:10.1001/ jama.1982.03320290017021)

58 Gankam Kengne F, Couturier BS, Soupart A \& Decaux G. Urea minimizes brain complications following rapid correction of chronic hyponatremia compared with vasopressin antagonist or hypertonic saline. Kidney International 201587 323-331. (doi:10.1038/ki.2014.273)

59 Verbalis JG, Goldsmith SR, Greenberg A, Korzelius C, Schrier RW, Sterns RH \& Thompson CJ. Diagnosis, evaluation, and treatment of hyponatremia: expert panel recommendations. American Journal of Medicine 2013126 S1-S42. (doi:10.1016/j. amjmed.2012.11.010)

Received in final form 23 August 2016

Accepted 8 September 2016

Accepted Preprint published online 8 September 2016 http://www.endocrineconnections.org DOI: 10.1530/EC-16-0046 (c) 2016 The authors Published by Bioscientifica Ltd

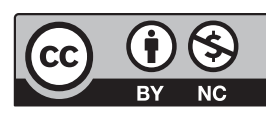

This work is licensed under a Creative Commons Attribution-NonCommercial 4.0 International License. 